|| ISSN(online): 2589-8698 || ISSN(print): 2589-868X || International Journal of Medical and Biomedical Studies

Available Online at www.ijmbs.info

Volume 3, Issue 2; February: 2019; Page No. 143-153

PubMed (National Library of Medicine ID: 101738825)

Index Copernicus Value 2017: 40.03

\title{
HYPOLIPIDEMIC AND ANTIOXIDANT EFFECTS OF CAMEL MILK IN HIGH FAT DIET FED HYPERLIPIDEMIC RATS
}

\author{
Suleiman Ahmed Isa ${ }^{1}$, Kasimu Ghandi Ibrahim ${ }^{2}$, Andrew Onu ${ }^{1}$, Sagir Kaka Shinkafi ${ }^{1}$, Rukayya Nuhu \\ Ismail $^{1}$, and Tijjani Salihu Shinkafi ${ }^{1, *}$ \\ ${ }^{1}$ Department of Biochemistry, Faculty of Science, Usmanu Danfodiyo University Sokoto PMB 2346, \\ Sokoto, Nigeria \\ ${ }^{2}$ Department of Physiology, College of Health Sciences, Usmanu Danfodiyo University Sokoto, PMB \\ 2346, Sokoto, Nigeria
}

Article Info: Received 4 February 2019; Accepted 28 February. 2019

Cite this article as: Isa, S., Ibrahim, K., Onu, A., Shinkafi, S., Ismail, R., \& Shinkafi, T. (2019). HYPOLIPIDEMIC AND ANTIOXIDANT EFFECTS OF CAMEL MILK IN HIGH FAT DIET FED HYPERLIPIDEMIC RATS. International Journal of Medical and Biomedical Studies, 3(2).

DOI: https://doi.org/10.32553/ijmbs.v3i2.131

Address for Correspondence: Suleiman Ahmed Isa Ph.D., Department of Biochemistry, Faculty of Science, Usmanu Danfodiyo University Sokoto, Nigeria

Conflict of interest: No conflict of interest.

\section{Abstract}

Milk is a rich and complete nutritive food provided by nature. The present study, reports the hypolipidemic and antioxidant effects of camel milk supplementation in the management of hyperlipidemia associated with obesity. Rats were rendered obese by feeding them with a high-fat diet for eight weeks to induce hyperlipidemia. The supplementation of camel milk as shown by atherogenic index, and a battery of biochemical markers of oxidative stress, lipid profile, antioxidant vitamins, markedly improved and ameliorated hyperlipidemia in rats. It also significantly $(p<0.05)$ lowered the elevated levels of aspartate aminotransferase, alanine aminotransferase, creatinine, and urea. The data provided evidence supporting the beneficial effect of camel milk on hyperlipidemia associated with obesity. The study assumes significance because of the fact that hyperlipidemia is associated with metabolic syndrome that leads to the development of chronic inflammatory diseases such as diabetes and atherosclerosis.

Keywords: Antioxidant; hypolipidemia; Camel milk; Obesity; High-Fat Diet; chronic inflammatory diseases

\section{Introduction:}

Hyperlipidemia is considered as the fifth leading cause of death in the world(1). Hyperlipidemia is caused by ingestion of largely fat containing diet of mostly animal origin in excess amount. Uncontrolled diet and sedentarylifestyle (physical inactivity) are some of the factors that are directly linked with overweight, obesity, metabolic syndrome, diabetes and atherosclerosis. They are seen as metabolic disorders associated with lipid metabolism. Metabolic disorders of lipid metabolism are characterized by high levels of lipids circulating in the blood(1). When the circulating lipids in the body rise, it leads to thedevelopment of a number of life threatening devastating chronic metabolic complications such as atherosclerosis, diabetes and cardiovascular diseases(2). 
Studies using both animals and humans have shown that accumulation of lipids in excess by non-adipose tissues leads to cell dysfunction and/or cell death. This phenomenon is referred to as lipotoxicity(3). Lipotoxicity may be detrimental to normal cellular homeostasis and as well as cell viability. Lipid accumulation in the pancreas, kidney, heart, skeletal muscle and liver play an important role in the pathogenesis of heart failure, obesity, and diabetes(4). Several intervention programs for the management of obesity and its major risk factor like hyperlipidemia include regular exercise, healthy eating behavior and use of hypolipidemic agents $(5,6)$.

The use of synthetic hypolipidemic agents is associated with adverse health consequences such as steatorrhea and stomach pain, drug interactions etc(6). The evidence is emerging supporting the potential hypolipidemic and antiobesity effect of milk including camel milk. High dairy intake has been shown to reduce the development of central obesity(7). The use of milk as afood and medicine has been known since time immemorial.Milk is a complete food provided by nature, especially to newborns. Milk is the main source of nutritive and biologically active therapeutic peptides that have thepotential for improving health. Milk food is rich in phospholipids that are of interest to dietitians. Depending on the type, phospholipids play an important role in lipid digestion, absorption and transport, theinflammatory processand signaling pathways(8). The proportion and composition of phospholipids differspecieswise. Camel milk is a good dietary source of phosphatidyl inositol, phosphatidyl serine, phosphatidyl ethanolamine and sphingomyelin(9). Previously, dietary sphingomyelin has been shown to decrease the absorption of intestinal cholesterol by up to $85 \%$ in rats(10). Interestingly, numerous studies have shown that camel milk has a higher content of phospholipids and plasminogen when compared with cow milk, sheep milk, Indian Buffalo milk and even human milk $(9,11)$. This is particularly important because phospholipids and plasminogen are important components of the brain and possess antioxidant activity(12). Milk is also rich in calcium. Dietary calcium has also been shown to play a vital role in preventing cardiovascular disease by enhancing weight reduction in type-2 diabetic patients(13).

Camel milk has been shown to possess several other therapeutic potentials including antidiabetic(14-16), anti-infectious(17), immunostimulatory(18), antioxidant(19), wound healing, $(20,21)$ neuroprotective effects(22) in addition to several other properties. Supplementation of camel milk has been reported to increase the regeneration of $\beta$-cell mass thereby decreasing the insulin requirement in both humans and diabetic animal models(23).

Studies have suggested thata dietknown to contain asignificant amount of naturally occurring antioxidants appear to ameliorate most of the traits of obesity and hyperlipidemia(24, 25). Additionally, the antidiabetic effect of camel milk in both type-1 and type- 2 diabetes has been demonstrated at preclinical and clinical levels(23, 26). Recently, camel milk has also been shown to inhibit Smad1 and collagen type-IV expression in streptozotocin-induced diabetes nephropathy animal models(27). The other benefit of camel milk is that it is known to containother important concentrates including but not limited to carbohydrates, and proteins. The protein content includes the whey proteinssuch as lactoferrin, lactoperoxidase, lysozyme, and immunoglobulins besides other components $(19,20)$. Therefore, although the issue of food drug to treat diseases is still an issue of debate, camel milk may in future complement other therapies. Since camel milk is a rich sourceof phospholipidsbesides other important molecules, the present study was therefore designed to evaluate the beneficial effects of camel milk in the management of hyperlipidemia associated with obesity.

\section{Materials and Methods}

Chemicals and Reagents 
Analytical grade laboratory chemicals and reagents were used in this study. Total Cholesterol assay kit, Triglyceride assay kit, and HDL-C assay kit, (product of Randox), were used in this work. AST and ALT assay kits were the product of Randox laboratories, UK.

\section{Collection of Milk Sample}

The milk was collected by cameleer using hand milking from lactating camel (Camelusdromedarius), at Kara Market Sokoto, Nigeria. It was collected in a sterile screw jar and kept in a cool container with ice block until transported to the laboratory where it was kept at atemperature of $-4^{0} \mathrm{C}$. The $\mathrm{pH}$ of the milk was checked every day before administration, to monitor the freshness of the milk.

\section{Animals and Experimental Design}

Wistar albino rats of both sexes weighing between 150-220g were used for the study. The animals were purchased and allowed to acclimatize for 7 days before the commencement of the experiment. All animals were housed in cages (8 rats/ cage), and fed with pelletized growers' feed (Vital feed, Jos, Nigeria). The diet contains $54 \%$ carbohydrates, $13 \%$ fat, $10 \%$ proteins, $20 \%$ fiber, $2 \%$ normal supplement and $1 \%$ vitamin and water. The rats were allowed access to water ad libitum before and during the experimental period. This study was conducted in accordance with the standards set for the use and care of laboratory animals and the protocol approved by the Ethical committee of the Usmanu Danfodiyo University Sokoto-Nigeria.

\section{Grouping of Animals}

Animals were randomly divided into five (5) groups of eight (8) rats each and treated as follows:

Group I: Normal diet

Group II: High-fat diet only

Group III: High-fat diet treated with camel milk (5mls/Kg BW/day)

Group IV: High-fat diet treated with camel milk (10mls/Kg BW/day)
Group V: High-fat diet treated with Atorvastatin (20mg/70Kg BW, Atorvastatin)

\section{Induction of Hyperlipidemia}

Rats were placed on ahigh-fat diet except for the control group(for eight weeks). The composition of the diet is in accordance with the method of Kim et al., (2005)(28) with some modification. The high fat diet contained (fat 46\% [animal fats], carbohydrates $24 \%$ [maize], protein $20.3 \%$ [soy beans], fibre $5 \%$, and salt mixture $3.7 \%$ and vitamin mixture $1 \%$ ).

\section{Biochemical Analysis}

Twenty-four hours after the last treatment, the animals were anesthetized with chloroform vapor and blood samples were collected through thecardiac puncture into labeled tubes. Prior to this, the animals were subjected to overnight fasting. The blood samples collected were allowed to clot and centrifuged at $4000 \mathrm{~g}$ for ten minutes. The sera obtained were pipetted into labeled test tubes for biochemical analysis.

Determination of Lipid Profile: Serum total cholesterol (TC) was estimated by anenzymatic method of Allain(1974)(29). Serum HDL- C was estimated by theenzymatic method of Burstein et al.,(30)using Randox Kit. Serum Triglyceride was assayed by the method of Tietz(31) using Randox Kit. Serum LDL- C was calculated using the method of Friedewald et al.,(32)

Estimation of Atherogenic Index: This was calculated as the ratio of LDL-cholesterol to HDLcholesterol according to Abbott et al.,(33).

Determination of Oxidative stress markers:Antioxidant vitamins (Vitamin A, C, and $E)$ were determined by the modified method of Godala et al., (2014) (34).Catalase activity was assayed using the method of Beers and Sizer (35). Reduced Glutathione was assayed according to Patterson and Lazarow(36). Malondialdehyde (MDA) as a marker of lipid peroxidation was measured using thethiobarbituric acid reactive substances (TBARS) method of Gutteridge and Quinlan(37). 
Estimation of Liver and Kidney function parameters: Aspartate aminotransferase (AST) and alanine aminotransferase were estimated using Reitman and Frankel method(38).Urea and creatinine levels were determined using the method ofFewcettand Scott(39).

\section{Data Analysis}

Data were analyzed using Student's t-test where two variables are compared and one-way analysis of variance (ANOVA) for more than two variables using Graph pad instat software (version 5 San Diego, USA). Results were considered statistically significant at $p<0.05$. All the values presented in this article are expressed as mean \pm standard deviation.

\section{Results}

The effect of high-fat-diet (HFD) on lipid profile is presented in table 1 . The result shows that eight weeks HFD feeding in rats was associated with dyslipidemia. There was a significant increase $(p<0.05)$ in serum total cholesterol (TC), triglycerides (TAG), low-density lipoprotein cholesterol ( $L D L-C)$, very low density lipoprotein cholesterol (VLDL-C), and a significant decrease $(p<0.05)$ in high-density lipoprotein cholesterol (HDL-C) in HFD rats as compared with control group. However, a significant decrease $(p<0.05)$ in TC, TAG, LDL-C, VLDL-C, and a significant increase $(p<0.05)$ in HDL-C was observed in HFD treated with camel milk group as compared with HFD untreated group. The results also indicate asignificant decrease $(P<0.05)$ in $T C$, TAG, and LDL-C in a group dosed with $20 \mathrm{mg} / 70 \mathrm{~kg}$ atorvastatin in comparison with high-fat diet untreated group.

The result of the atherogenic index is presented in Figure 1. The atherogenic index significantly decreased in groups supplemented with camel milk as compared with high-fat diet non-treated. Atherogenic index of the high-fat diet group significantly increased compared to control. No significant variation between high-fat diet treated with camel milk groups and thegroup treated with atorvastatin.
The result of the effect of high-fat diet and supplementation with camel milk on markers of oxidative stress is presented in Table 2 . The result indicates significant $(P<0.05)$ decrease in MDA of camel milk supplemented groups as compared with high-fat diet non-supplemented groups. The result also indicates that catalase and reduced glutathione were reduced significantly in high-fat diet untreated group compared to control.

The result of the effect of high-fat diet and supplementation with camel milk on antioxidant vitamins is presented in Table 3 . The result indicates significant $(P<0.05)$ decrease in antioxidant vitamins (Vit. A, C and E) in high-fat diet non-supplemented group compared to control. An increase in these vitamins was also observed in camel milk treated group compared to high-fat diet non-treated group.

The result of the effect of high-fat diet and supplementation with camel milk on some liver and kidney function parameter is presented in Table 4 . The result shows a significant increase $(p<0.05)$ in the levels of ALT, AST, creatinine and in high-fat diet non-supplemented group compared to control. However, there was a significant decrease in these values in the camel milk supplemented groups compared to nonsupplemented groups. The levels of urea and creatinine also follows asimilar pattern to that of AST and ALT. Creatinine levels were significantly high $(p<0.05)$ in high-fat diet non-supplemented group compared to control. However, there was a significant decrease in these values in the camel milk supplemented groups compared to non-supplemented groups.

\section{Discussion}

In this study, we determined the beneficial effect of camel milk supplementation to high-fat induced hyperlipidemia rat model. The metabolic alterations due to the effect of camel milk on markers of oxidative stress, lipid profile, and antioxidant vitamins were determined. Equally, the effect of camel milk on some liver and kidney function parameters such as aspartate 
aminotransferase, alanine aminotransferase, creatinine, and urea were alsostudied. The results of the effect of high-fat-diet on lipid profile (Table 1.) shows that eight weeks high-fat diet feeding in rats was associated with hyperlipidemia and dyslipidemia as evident of increase levels of serum triacylglycerols, total cholesterol, LDL-cholesterol, and VLDLcholesterol. These findings are in agreement with previously reported data(40). Obesity has been shown to play a very important role in developing dyslipidemia, diabetes and cardiovascular diseases $(41,42)$. The changes that occur in dyslipidemic obesity are largely due to increased lipid accumulation in non-adipose tissues as a result of the influx of excess nonesterified fatty acids $(43,44)$. In line with the current findings, it has also been suggested that lipid structure and composition in addition to high-fat diet consumption have an effect on plasma lipoprotein(45). Enhanced deesterification of free fatty acids and decreased lipoproteins in the body has been described to cause hyperlipidemia(46). This leads to increase in body mass with a concomitant increase in atherogenic markers such as weight which is an independent marker of obesity.

Unhealthy lifestyle such as bad eating habit, a sedentary lifestyle is often described as the hallmark of chronic conditions such as metabolic syndrome, diabetes, and obesity. In a study, Stefler et al.,(47)has shown that unhealthy diet is the main culprit to be blamed for the high mortality rate in a European population as a result of cardiovascular disease. On the other hand, a healthy diet might prevent the development of these conditions leading to a better life. This is evident in the Mediterranean population whose diet has been shown to reduce cardiovascular disease risk and thus preventing chronic complications(48, 49). Fermented milk products such as yogurt and cheese are commonly found in Mediterranean diet. Milk in itself is a complete food having different constituents with so many biological roles. Dietary phospholipids, for example, has been demonstrated to reduced cholesterol(10). This can have some effect in preventing cardiovascular diseases. Dietary calcium is another example, it has been shown to reduce weight and thus, may prevent cardiovascular diseases (13).

As with Korish et al.,(50), it is vividly clear that camel milk supplementation to hyperlipidemic rats significantly reduced the atherogenic index (Figure 1) and has a hypolipidemic effect Table 1. When compared with either control (group I) or treated groups, group II(high-fat diet alone) showed much higher Al than group III and IV that showed a significant volume dependent reduction of atherogenic index and a similar situation was observed in the case of group $V$ that was treated with atorvastatin. The mechanism of hypolipidemic effect of camel milk might be related to the ability of phospholipids in the milk to stimulate the uptake of intestinal cholesterol and hence the increase in HDL levels in group III-V as opposed to group II. Eckhardt et al., (10) have shown that dietary sphingomyelin decreased the absorption of intestinal cholesterol by up to $85 \%$ in rats. Interestingly, numerous studies have shown that camel milk has a higher content of phospholipids and plasminogen when compared with cow milk, sheep milk, Indian Buffalo milk and even human $\operatorname{milk}(9,11)$. Whey protein administered to obese rats has been shown to cause hypolipidemic effect (51).

Hyperlipidemia plays a role in the pathogenesis of chronic inflammatory condition such as diabetes, metabolic syndrome, and obesity. One of the identified mechanisms of pathophysiology in these conditions is by alteration of a redox system. In Table 3, the result of the effect of high-fat diet and supplementation with camel milk on markers of oxidative stress is presented.Studies have demonstrated the antioxidant effect of camel milk experimentally and indicating the potential for camel milk as complementary agent for the management of chronic inflammatory diseases $(21,52)$. This can be evidently seen as significant $(P<0.05)$ decrease in antioxidant vitamins (Vit. A, C and E) 
in high-fat diet non-supplemented group compared to control. An increase in these vitamins was observed in camel milk treated group compared to high-fat diet non-treated group.

The liver plays a key role in many of the processes of intermediary metabolism. Its functions include carbohydrates, proteins, and lipid synthesis. In the liver, cholesterol is esterified with fatty acid and released into the circulation. The liver incorporates lipids into lipoproteins before releasing them into the plasma. Thus in the event of hyperlipidemia, normal cellular homeostasis is compromised. Ultimately organs such as kidney and heart are exposed to thedeleterious assault of metabolic waste. In the observed result, the resultant increase in ALT and AST of group II when compared to group I may be due to theaccumulation of excess lipids in hepatocytes leading to cellular dysfunction.In hyperlipidemia, hepatic uptake of free fatty acid is directly related to plasma free fatty acid(53). These free fatty acids are oxidized with concomitant released of reactive oxygen species (ROS) which induced cellular injury and dysfunction(54). In hepatocellular injury, ALT and AST levels are increased in the serum. Importantly, a significant decrease in ALT and AST levels in groups supplemented with camel milk in a dosedependent manner was observed Table 4. We suggest that this effect may be due to the antioxidant activity reported for camel milk(52). Similarly, the observed decrease of creatinine and urea levels in the groups supplemented with camel milk may be due to the effect of camel milk in ameliorating hepatocellular injury resulting from hyperlipidemia thereby restoring protection to the nephrons.

Table 1: Effect of eight weeks high-fat diet feeding on lipid profile in the rat.

\begin{tabular}{|c|c|c|c|c|c|}
\hline \multirow{2}{*}{$\begin{array}{l}\text { Parameter } \\
\text { (mg/dl) }\end{array}$} & \multicolumn{5}{|c|}{ Groups } \\
\hline & 1 & II & III & IV & \\
\hline TAG & $151.5 \pm 8.7$ & $284.3 \pm 69.9 *$ & $205.7 \pm 10.7$ & $139.9 \pm 3.1 *$ & $140.2 \pm 15.6$ \\
\hline TC & $124.9 \pm 15.0$ & $195.3 \pm 20.9 *$ & $151.8 \pm 6.0 *$ & $152.8 \pm 6.0^{*}$ & $136.3 \pm 36.7$ \\
\hline HDL-C & $66.9 \pm 5.3$ & $51.1 \pm 5.1$ & $58.7 \pm 3.7$ & $75.3 \pm 3.5 *$ & $78.9 \pm 20.9$ \\
\hline LDL-C & $27.16 \pm 7.2$ & $92.9 \pm 9.9 *$ & $55.6 \pm 1.5^{*}$ & $44.04 \pm 8.8$ & $37.1 \pm 0.8$ \\
\hline VLDL-C & $30.8 \pm 2.5$ & $51.3 \pm 5.9 *$ & $37.5 \pm 0.8$ & $33.5 \pm 9.4$ & $20.3 \pm 15.0$ \\
\hline
\end{tabular}

Table 1: Abbreviations: TAG, triglycerides; TC, total cholesterol; HDL-C, high-density lipoprotein cholesterol; LDL-C, low-density lipoprotein cholesterol; VLDL-C, very low-density lipoprotein cholesterol. Group I: Control; Group II: High fat diet untreated; Group III: High fat diet treated with camel milk ( $5 \mathrm{mls} / \mathrm{kg}$ b.w/day); Group IV: High fat diet treated with camel milk ( $10 \mathrm{mls} / \mathrm{Kg}$ b.w/day); Group V: High fat diet treated with $20 \mathrm{mg} / 70 \mathrm{Kg}$ Atorvastatin. Values are expressed as mean \pm Standard deviation. * means $p<0.05$ compared to control. 
Table 2: Effect of supplementation with camel milk on markers of oxidative stress in hyperlipidemic rats

\begin{tabular}{lccccc}
\hline $\begin{array}{l}\text { Parameter } \\
(\mathrm{mmol} / \mathrm{L})\end{array}$ & $\mathrm{I}$ & $\mathrm{II}$ & $\mathrm{III}$ & $\mathrm{IV}$ & $\mathrm{V}$ \\
\hline CAT & $8.2 \pm 2.6^{1}$ & $3.2 \pm 1.7^{1,2}$ & $9.2 \pm 0.9$ & $13.9 \pm 2.5^{3}$ & $9.9 \pm 1.4$ \\
MDA & $7.7 \pm 0.6^{1}$ & $21.2 \pm 0.5^{1,2}$ & $14.6 \pm 0.7^{2}$ & $17.6 \pm 1.2^{3}$ & $17.6 \pm 0.6^{4}$ \\
RGSH & $112.5 \pm 2.6$ & $82.8 \pm 0.6^{2}$ & $83.9 \pm 1.4$ & $93.7 \pm 1.8$ & $95.1 \pm 1.7$ \\
\hline
\end{tabular}

Table 2: Abbreviation: CAT, catalase; MDA, malondialdehyde; RGSH, reduced glutathione. Group I: Control; Group II: High fat diet untreated; Group III: High fat diet treated with camel milk $(5 \mathrm{mls} / \mathrm{kg}$ b.w/day); Group IV: High fat diet treated with camel milk (10mls/Kg b.w/day); Group V: High fat diet treated with $20 \mathrm{mg} / 70 \mathrm{Kg}$ Atorvastatin. Values are expressed as mean \pm Standard deviation. Data carrying the same superscript figure on the same row are significantly different $(p<0.05)$.

Table 3: Effect of supplementation with camel milk on antioxidant vitamins in hyperlipidemic rats.

\section{Groups}

Parameter

\begin{tabular}{llllll} 
& I & II & III & IV & V \\
\hline Vit.A $(\mu \mathrm{M})$ & $1.67 \pm 0.16$ & $0.21 \pm 0.14^{*}$ & $1.31 \pm 0.38$ & $1.47 \pm 0.19$ & $1.16 \pm 1.48$ \\
Vit.C $(\mu \mathrm{mol} / \mathrm{L})$ & $371.50 \pm 38.33$ & $154.50 \pm 29.63 *$ & $250.50 \pm 23.34 *$ & $383.55 \pm 4.74$ & $252.53 \pm 44.5$ \\
Vit.E $(\mathrm{mg} / \mathrm{dl})$ & $42.7 \pm 0.57$ & $8.75 \pm 1.77^{*}$ & $10.65 \pm 7.42$ & $17.6 \pm 6.51 *$ & $19.45 \pm 5.59 *$
\end{tabular}

Table 3: Abbreviation: Vit.A, Vitamin A; Vit.C, Vitamin C; Vit.E, Vitamin E; Group I: Control; Group II: High fat diet untreated; Group III: High fat diet treated with camel milk ( $5 \mathrm{mls} / \mathrm{kg}$ b.w/day); Group IV: High fat diet treated with camel milk $(10 \mathrm{mls} / \mathrm{Kg}$ b.w/day); Group V: High fat diet treated with $20 \mathrm{mg} / 70 \mathrm{Kg}$ Atorvastatin. Values are expressed as mean \pm Standard deviation. * means $p<0.05$ compared to control.

Table 4: Effect of supplementation with camel milk on liver and kidney function parameters in hyperlipidemic rats.

\begin{tabular}{llllll}
\hline & \multicolumn{5}{c}{ Groups } \\
Parameter & I & II & IV & V & \\
\hline ALT (IU/L) & $29.2 \pm 0.3^{1}$ & $47.4 \pm 0.6^{1234}$ & $34.7 \pm 0.5^{2}$ & $32.4 \pm 0.4^{3}$ & $33.7 \pm 0.3^{4}$ \\
AST (IU/L) & $128 \pm 0.8^{1}$ & $160 \pm 2.9^{1234}$ & $149.4 \pm 1.1^{1}$ & $139.5 \pm 0.8^{3}$ & $139.6 \pm 2.8^{4}$ \\
Crea (mmol/I) & $15.0 \pm 2.83^{1}$ & $23.6 \pm 0.28^{1}$ & $16.05 \pm 2.19$ & $15.95 \pm 1.06$ & $16.55 \pm 1.49$ \\
Urea (mmol/l) & $4.92 \pm 0.3^{1}$ & $6.60 \pm 0.71^{1}$ & $5.32 \pm 0.12$ & $5.34 \pm 0.15$ & $5.38 \pm 0.04$ \\
\hline
\end{tabular}


Table 4: Abbreviation: ALT, alanine transaminase; AST, aspartate transaminase; Crea, Creatinine; Group I: Control; Group II: High fat diet untreated; Group III: High fat diet treated with camel milk $(5 \mathrm{mls} / \mathrm{kg}$ b.w/day); Group IV: High fat diet treated with camel milk (10mls/Kg b.w/day); Group V: High fat diet treated with $20 \mathrm{mg} / 70 \mathrm{Kg}$ Atorvastatin. Values are expressed as mean \pm Standard deviation. Data having the same superscripts figure on the same row are significantly different $(p<0.05)$.

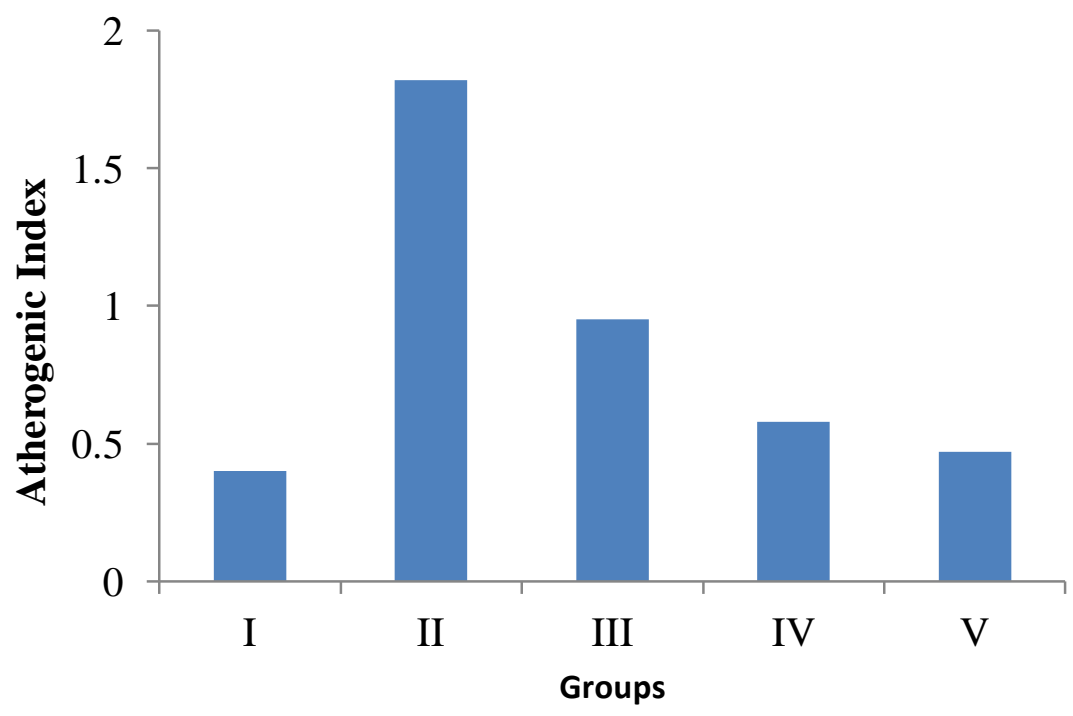

Figure 1: Mean AtherogenicIndex.Group I: Control; Group II: High fat diet untreated; Group III: High fat diet treated with camel milk ( $5 \mathrm{mls} / \mathrm{kg}$ b.w/day); Group IV: High fat diet treated with camel milk $(10 \mathrm{mls} / \mathrm{Kg} \mathrm{b.w/day);} \mathrm{Group} \mathrm{V:} \mathrm{High} \mathrm{fat} \mathrm{diet} \mathrm{treated} \mathrm{with} 20 \mathrm{mg} / 70 \mathrm{Kg}$ Atorvastatin. Values are expressed as mean \pm Standard deviation.

\section{Conclusion:}

The findings support the potential complementary beneficial hypolipidemic as well as the antioxidant effect of camel milk. The results, when taken together, provided evidence for the potential preventive effect of camel milk in the management of chronic conditions associated with hyperlipidemia.

\section{Acknowledgments:}

The authors are grateful to the laboratory technicians of the Department of Biochemistry, Usmanu Danfodiyo University for Technical support.

\section{Author contributions:}

SAI,KGI, and TSS designed the study and analyzed the data. SAI and TSS wrote the paper. AO, SKS, and RNI performed the animal experiments. SAI, $\mathrm{KGI}$, and TSS provided the reagents.

\section{References}

1. Jacobson TA, Miller $M$, Schaefer EJ. Hypertriglyceridemia and cardiovascular risk reduction. Clin Ther. 2007;29(5):763-77.

2. Wierzbicki AS. Further options for treating lipids in people with diabetes: targeting LDLcholesterol and beyond. Diabet Med. 2018. doi:10.1111/dme.13667.

3. Schaffer JE. Lipotoxicity: when tissues overeat. Curr Opin Lipidol. 2003;14(3):281-7.

4. Van Herpen NA, Schrauwen-Hinderling VB. Lipid accumulation in non-adipose tissue and lipotoxicity. Physiol Behav. 2008;94(2):23141

5. Miller YD, Dunstan DW. The effectiveness of physical activity interventions for the treatment of overweight and obesity and type 2 diabetes. J Sci Med Sport. 2004;7(1 Suppl):52-9. 
6. Filippatos TD, Derdemezis CS, Gazi IF, Nakou ES, Mikhailidis DP, Elisaf MS. Orlistatassociated adverse effects and drug interactions: a critical review. Drug Saf. 2008;31(1):53-65.

7. Holmberg $S$, Thelin A. High dairy fat intake related to less central obesity: a male cohort study with 12 years' follow-up. Scand I Prim Health Care. 2013;31(2):89-94.

8. Alhaider AA, Abdel Gader AG, Almeshaal N, Saraswati S. Camel milk inhibits inflammatory angiogenesis via downregulation of proangiogenic and proinflammatory cytokines in mice. APMIS. 2014;122(7):599-607.

9. Garcia C, Lutz NW, Confort-Gouny S, Cozzone PJ, Armand $M$, Bernard $M$. Phospholipid fingerprints of milk from different mammalians determined by 31P NMR: towards specific interest in human health. Food Chem. 2012;135(3):1777-83.

10. Eckhardt ER, Wang DQ, Donovan JM, Carey MC. Dietary sphingomyelin suppresses intestinal cholesterol absorption by decreasing thermodynamic activity of cholesterol monomers. Gastroenterology. 2002;122(4):948-56.

11. Morrison WR. Fatty acid composition of milk phospholipids. III. Camel, ass, and pig milks. Lipids. 1968;3(2):107-10.

12. Yavin E, Brand A, Green P. Docosahexaenoic acid abundance in the brain: a biodevice to combat oxidative stress. Nutr Neurosci. 2002;5(3):149-57.

13. Shahar DR, Abel R, Elhayany A, Vardi $H$, Fraser $D$. Does dairy calcium intake enhance weight loss among overweight diabetic patients? Diabetes Care. 2007;30(3):485-9.

14. Sboui $A$, Khorchani T, Djegham M, Agrebi $A$, Elhatmi $\mathrm{H}$, Belhadj $\mathrm{O}$. Anti-diabetic effect of camel milk in alloxan-induced diabetic dogs: a dose-response experiment. J Anim Physiol Anim Nutr (Berl). 2010;94(4):540-6.

15. Malik A, Al-Senaidy A, Skrzypczak-Jankun E, Jankun J. A study of the anti-diabetic agents of camel milk. Int $J \mathrm{Mol}$ Med. 2012;30(3):585-92.
16. Korish AA. The antidiabetic action of camel milk in experimental type 2 diabetes mellitus: an overview on the changes in incretin hormones, insulin resistance, and inflammatory cytokines. Horm Metab Res. 2014;46(6):404-11.

17. Cardoso RR, Ponte $M$, Leite V. Protective action of camel milk in mice inoculated with Salmonella enterica. Isr Med Assoc J. 2013;15(1):5-8.

18. Ebaid H, Abdel-Salam B, Hassan I, Al-Tamimi J, Metwalli A, Alhazza I. Camel milk peptide improves wound healing in diabetic rats by orchestrating the redox status and immune response. Lipids Health Dis. 2015;14:132.

19. Habib HM, Ibrahim WH, Schneider-Stock R, Hassan HM. Camel milk lactoferrin reduces the proliferation of colorectal cancer cells and exerts antioxidant and DNA damage inhibitory activities. Food Chem. 2013;141(1):148-52.

20. Abdel-Salam BK. Modulatory effect of whey proteins in some cytokines involved in wound healing in male diabetic albino rats. Inflammation. 2014;37(5):1616-22.

21. Arab HH, Salama SA, Eid AH, Omar HA, Arafa el SA, Maghrabi IA. Camel's milk ameliorates TNBS-induced colitis in rats via downregulation of inflammatory cytokines and oxidative stress. Food Chem Toxicol. 2014;69:294-302.

22. Ajarem J, Allam AA, Ebaid H, Maodaa SN, AlSobeai SM, Rady AM, et al. Neurochemical, structural and neurobehavioral evidence of neuronal protection by whey proteins in diabetic albino mice. Behav Brain Funct. 2015;11:7.

23. Agrawal RP, Saran S, Sharma P, Gupta RP, Kochar DK, Sahani MS. Effect of camel milk on residual beta-cell function in recent onset type 1 diabetes. Diabetes Res Clin Pract. 2007;77(3):494-5.

24. Abdali D, Samson SE, Grover AK. How effective are antioxidant supplements in obesity and diabetes? Med Princ Pract. 2015;24(3):201-15. 
25. Yun JW. Possible anti-obesity therapeutics from nature--a review. Phytochemistry. 2010;71(14-15):1625-41.

26. Agrawal RP, Jain S, Shah S, Chopra A, Agarwal V. Effect of camel milk on glycemic control and insulin requirement in patients with type 1 diabetes: 2-years randomized controlled trial. Eur $J$ Clin Nutr. 2011;65(9):1048-52.

27. Korish AA, Abdel Gader AG, Korashy HM, AlDrees AM, Alhaider AA, Arafah MM. Camel milk attenuates the biochemical and morphological features of diabetic nephropathy: inhibition of Smad1 and collagen type IV synthesis. Chem Biol Interact. 2015;229:100-8.

28. Kim T, Chan KK, Dhaliwall JK, Huynh $N$, Suen $\mathrm{R}$, Uchino $\mathrm{H}$, et al. Anti-atherogenic effect of insulin in vivo. J Vasc Res. 2005;42(6):45562. doi:10.1159/000088099.

29. Allain CC, Poon LS, Chan CS, Richmond W, Fu PC. Enzymatic determination of total serum cholesterol. Clin Chem. 1974;20(4):470-5.

30. Burstein M, Scholnick HR, Morfin R. Rapid method for the isolation of lipoproteins from human serum by precipitation with polyanions. J Lipid Res. 1970;11(6):583-95.

31. Tietz NW, Repique EV. Proposed standard method for measuring lipase activity in serum by a continuous sampling technique. Clin Chem. 1973;19(11):1268-75.

32. Friedewald WT, Levy RI, Fredrickson DS. Estimation of the concentration of lowdensity lipoprotein cholesterol in plasma, without use of the preparative ultracentrifuge. Clin Chem. 1972;18(6):499502

33. Wilson PW, Abbott RD, Castelli WP. High density lipoprotein cholesterol and mortality. The Framingham Heart Study. Arteriosclerosis. 1988;8(6):737-41.

34. Godala M, Materek-Kusmierkiewicz I, Moczulski D, Rutkowski M, Szatko F, Gaszynska $E$, et al. [Estimation of plasma vitamin $A, C$ and $E$ levels in patients with metabolic syndrome]. Pol Merkur Lekarski. 2014;36(215):320-3.
35. Beers RF, Jr., Sizer IW. A spectrophotometric method for measuring the breakdown of hydrogen peroxide by catalase. J Biol Chem. 1952;195(1):133-40.

36. Patterson JW, Lazarow A. Determination of glutathione. Methods Biochem Anal. 1955;2:259-78.

37. Gutteridge JM, Quinlan GJ. Malondialdehyde formation from lipid peroxides in the thiobarbituric acid test: the role of lipid radicals, iron salts, and metal chelators. $J$ Appl Biochem. 1983;5(4-5):293-9.

38. Reitman S, Frankel S. A colorimetric method for the determination of serum glutamic oxalacetic and glutamic pyruvic transaminases. Am J Clin Pathol. 1957;28(1): 56-63

39. Fawcett JK, Scott JE. A rapid and precise method for the determination of urea. J Clin Pathol. 1960;13:156-9.

40. Woo MN, Bok SH, Lee MK, Kim HJ, Jeon SM, Do GM, et al. Anti-obesity and hypolipidemic effects of a proprietary herb and fiber combination (S\&S PWH) in rats fed high-fat diets. J Med Food. 2008;11(1):169-78.

41. Fried $M$, Hainer $V$, Basdevant $A$, Buchwald $H$, Dietel $\mathrm{M}$, Finer $\mathrm{N}$, et al. [Interdisciplinary European guidelines on surgery for severe obesity]. Rozhl Chir. 2008;87(9):468-76.

42. Lavie CJ, Ventura HO, Milani RV. The "obesity paradox": is smoking/lung disease the explanation? Chest. 2008;134(5):896-8.

43. Grundy SM. Obesity, metabolic syndrome, and cardiovascular disease. J Clin Endocrinol Metab. 2004;89(6):2595-600.

44. Despres JP, Lemieux I, Bergeron J, Pibarot $P$, Mathieu $P$, Larose $E$, et al. Abdominal obesity and the metabolic syndrome: contribution to global cardiometabolic risk. Arterioscler Thromb Vasc Biol. 2008;28(6): 1039-49.

45. Zulet MA, Martinez JA. Corrective role of chickpea intake on a dietary-induced model of hypercholesterolemia. Plant Foods Hum Nutr. 1995;48(3):269-77.

46. Jensen MD. Role of body fat distribution and the metabolic complications of obesity. J Clin 
Endocrinol Metab. 2008;93(11 Suppl 1):S5763.

47. Stefler $D$, Pikhart $H$, Jankovic $N$, Kubinova $R$, Pajak A, Malyutina $S$, et al. Healthy diet indicator and mortality in Eastern European populations: prospective evidence from the HAPIEE cohort. Eur J Clin Nutr. 2014;68 (12):1346-52.

48. Stefler $D$, Malyutina $S$, Kubinova R, Pajak A, Peasey $A$, Pikhart $H$, et al. Mediterranean diet score and total and cardiovascular mortality in Eastern Europe: the HAPIEE study. Eur J Nutr. 2015.

49. Bonaccio M, lacoviello L, de Gaetano G, Moli-Sani I. The Mediterranean diet: the reasons for a success. Thromb Res. 2012;129(3):401-4.

50. Korish AA, Arafah MM. Camel milk ameliorates steatohepatitis, insulin resistance and lipid peroxidation in experimental non-alcoholic fatty liver disease. BMC Complement Altern Med. 2013;13:264.

51. El-Shinnawy NA, Abd Elhalem SS, Haggag NZ, Badr G. Ameliorative role of camel whey protein and rosuvastatin on induced dyslipidemia in mice. Food Funct. 2018;9(2):1038-47.

52. Al-Ayadhi LY, Elamin NE. Camel Milk as a Potential Therapy as an Antioxidant in Autism Spectrum Disorder (ASD). Evid Based Complement Alternat Med. 2013;2013: 602834

53. Fabbrini E, Sullivan S, Klein S. Obesity and nonalcoholic fatty liver disease: biochemical, metabolic, and clinical implications. Hepatology. 2010;51(2):679-89.

54. Kalogeris $\mathrm{T}$, Bao $\mathrm{Y}$, Korthuis RJ. Mitochondrial reactive oxygen species: a double edged sword in ischemia/reperfusion vs preconditioning. Redox Biol. 2014;2:70214. 